\title{
UMA LEITURA CRÍTICA DO BIOCENTRISMO DE PAUL TAYLOR A PARTIR DE JAMES STERBA ${ }^{1}$
}

\author{
CARMELITA SCHULZE \\ Mestranda do Programa de Pós-graduação em Filosofia (Ética e Filosofia Política), UFSC
}

\begin{abstract}
This article examine critically the James Sterbas' biocentric project on his article, "A Biocentrist Strikes Back". On this Sterbas' article, he propose to defend biocentrism from three critics. From the critic that this theory benefits the human specie on damage of other species, from the critic that the biocentrism suppose that exist harmony on the nature and, lately, from the critic that it can not defend itself from the acusation that cann not define what have intrinsic value. By these answers, we will analyse Sterba's critic upon the biocentrism of Paul Taylor. For example, the Sterbian critic that Taylor presupposes humans are saints and that in his theory Taylor gives preference to the human over other species.
\end{abstract}

Key words: Paul W. Taylor, biocentrism, James Sterba, intrinsic value.

\section{Resumo}

Este artigo analisa a proposta biocêntrica encontrada no artigo, "A Biocentrist Strikes Back" (Um biocentrista revida), de James Sterba, que se propõe a defender o biocentrismo de três acusações: de que favorece a espécie humana em detrimento das demais, de que pressupõe que haja uma harmonia na natureza, e de que não consegue distinguir o que possui, do que não possui, valor intrínseco. Além dessas respostas, serão analisadas as críticas de Sterba a Paul Taylor, por exemplo, a de que Taylor pressupõe que os humanos sejam santos e de que há na teoria biocêntrica deste uma preferência pela espécie humana sobre as demais.

Palavras-chave: Paul W. Taylor, biocentrismo, James Sterba, valor intrínseco.

\section{Introdução}

O que James Sterba se propõe no artigo, "Um biocentrista revida" é defender o biocentrismo de três acusações: primeira, de que favorece a espécie humana em detrimento das demais; segunda, de que pressupõe que haja uma harmonia na natureza; terceira, de que não consegue distinguir o que possui, do que não possui, valor intrínseco. Sterba afirma que a essas acusações o biocentrismo deve responder com êxito, para existir como racionalmente justificado. Sterba garante que consegue responder às três acusações, com o biocentrismo que propõe.

\section{O conceito de igualdade e a crítica a Taylor}

A origem do conceito de igualdade, em que se baseia para defender a igualdade entre as espécies, é a analogia que faz entre a ética humana e a ética ambiental. Essa igualdade, segundo o autor, se assemelha mais à igualdade presente no libertarianismo e no liberalismo bem-estarista 
do que à igualdade socialista. Tais conceitos de igualdade com essa maior semelhança são assim definidos:

No libertarianismo, todos têm igual direito à liberdade, embora esse direito imponha alguns limites na realização do auto-interesse, ele diz para nos deixarmos refrear para ajudar os outros em necessidades severas. No liberalismo bem-estarista, todos têm igual direito ao bem-estar e à oportunidade, mas esses direitos não nos obrigam a suprir a todos exatamente com as mesmas fontes. No socialismo, todos têm igual direito a se autodesenvolverem, e embora esse direito deva assegurar a todos os mesmos recursos, ele ainda sanciona algum nível de autopreferência. ${ }^{2}$

O fato da concepção biocêntrica de Sterba apoiar-se em algo mais geral do que o apoio sobre o qual o biocentrismo de Taylor se sustenta permite ao primeiro evitar ser a favor da espécie humana. Essa tendenciosidade ocorre em Taylor, aponta Sterba:

[...] Ao discutir as aplicações práticas de sua visão, Taylor permite que agridamos interesses básicos de animais e plantas (silvestres), até mesmo para realizar necessidades humanas não-básicas, possibilitando isso ser compatível com a atitude de respeito à natureza, contanto que nenhum caminho alternativo para satisfazer essas necessidades humanas não-básicas que envolva menores prejuízos esteja disponível. $^{3}$

Realmente, a possibilidade de os humanos realizarem seus interesses não-básicos em detrimento dos interesses básicos dos animais e plantas selvagens é admitida por Taylor, conforme se pode ver nas passagens de, Respect for Nature, nas quais são apresentados o princípio do mal menor e o modo pelo qual este deve ser aplicado:

O princípio do mal menor, por outro lado, aplica-se aos conflitos entre os interesses básicos de animais e plantas e aqueles interesses humanos não-básicos tão altamente valorados que até uma pessoa que respeita a natureza não estaria disposta a absterse de buscá-los, sabendo que a realização de tais interesses acarreta prejuízos ao mundo natural. ${ }^{4}$

O princípio [do mal menor] estabelece a exigência de que ações realizadas por indivíduos na busca da realização de fins que situam-se no cerne de concepções racionais do seu verdadeiro bem devem ser tais, que, nenhum caminho alternativo para a realização desses fins produza menores danos às coisas selvagens. Como antes, o teste chave para a permissibilidade moral é que certos interesses não-básicos de humanos possam ser realizados somente sob a condição da minimização de danos cometidos em relação a não-humanos e ecossistemas naturais. ${ }^{5}$

O apoio no libertarianismo e no liberalismo bem-estarista permite a Sterba, segundo ele, 
fundar a igualdade entre as espécies sobre dois princípios: um, compreendendo a defesa, e, outro, a não-defesa em relação a agressões, que se aplicam a todos os agentes capazes de entender e agir baseados neles. Estes princípios consistem no seguinte:

O princípio de defesa permite ações em defesa tanto de necessidades básicas quanto não-básicas contra a agressão de outros, mesmo que seja necessário matar ou danificar (prejudicar/machucar) esses outros, a menos que seja proibido.

O princípio de não-defesa proíbe defender necessidades não-básicas da agressão de outros, assumida como o único caminho para satisfazer necessidades básicas, se alguém pode razoavelmente esperar um nível comparável de proibição altruísta daqueles em favor dos quais está abrindo mão de se defender. ${ }^{6}$

O princípio da autodefesa em relação às agressões acima referidas, primeiramente, permite ao agente moral defender-se daquilo que vai contra sua pessoa e a pessoa daqueles que estão sob sua guarda e cuidados. Secundariamente, permite ao agente moral defender sua propriedade legítima e a propriedade legítima daqueles dos quais é obrigado a cuidar. Esse princípio é análogo ao princípio de autodefesa, existente na ética humana.

Este primeiro princípio também é considerado por Taylor como critério que deve ser atendido para se estabelecer a igualdade entre as espécies, no entanto, com o mesmo nome que ele possui na ética humana: princípio de autodefesa. Esse princípio, Taylor só concebe que pode ser legitimamente seguido pelo agente moral quando este, usando o cuidado racional, não pode evitar estar exposto aos perigos de um organismo que lhe é danoso e não pode prevenir-se dos danos às condições naturais que possibilitam ao agente moral existir e funcionar como um agente moral. ${ }^{7}$

A questão, de se o que Sterba considera propriedade legítima pertence, ou não, ao conjunto das condições que Taylor elenca como as que possibilitam ao agente moral existir e funcionar como tal, fica em aberto, já que Sterba não se detém, no artigo ora analisado, em definir o que entende por propriedade legítima.

No entanto, há um limite para a defesa do princípio de autodefesa de Sterba, justificado por esse mesmo princípio, que dá vez à ação do segundo princípio, sobre o qual Sterba fundamenta a igualdade entre as espécies: o da não-defesa. Este consiste na proibição de se defender necessidades não-básicas contra a agressão de outros que não têm alternativa para satisfazer suas necessidades básicas, se, quem é agredido pode racionalmente esperar um nível comparável de abstenção altruísta dos demais aos quais esses dois princípios se aplicam.

A referência que Sterba usa para demonstrar o que devemos entender por esse nível comparável de abstenção altruísta é um exemplo de sua ocorrência na ética humana. Ele ocorre quando, 
justificadamente, se permite ao pobre, o qual tem esgotados todos os outros meios legitimamente disponíveis para satisfazer suas necessidades básicas, tomar das posses excedentes (supérfluas) do rico a parte que realmente precisa para satisfazer suas necessidades básicas. Justificadamente lhe é permitido tomar tal atitude, porque o rico concorda que, se estivesse no lugar do pobre, esperaria poder também tomar essa posse, correspondendo, portanto, ao mesmo grau de altruísmo ${ }^{8}, 9$.

O princípio de não-defesa, continua Sterba, é simplesmente uma espécie de generalização neutra do princípio de agressão encontrado na ética humana. ${ }^{10}$ Assim, o princípio de defesa e o princípio de não-defesa, em conjunto, expressam os fundamentos do limite da autodefesa e da defesa dos membros da própria espécie em detrimento de outras espécies, de forma consistente com a igualdade entre as espécies.

\section{Necessidades básicas vs. necessidades não-básicas}

Taylor, no entanto, não concordaria que abrir mão da realização de necessidades não-básicas, por parte de um agente moral, em favor da realização de uma necessidade básica de alguém sobre o qual a moralidade se aplica só pode ser moralmente exigido se o agente puder esperar esse mesmo grau de altruísmo de quem é beneficiado. A discordância entre o argumento de Taylor e o de Sterba evidencia-se na passagem da obra de Taylor, na qual considera o paciente moral (moral subject) como aquele que merece respeito moral por ter um bem próprio a seu próprio modo, portanto, um valor inerente (inherent worth), e não por poder possibilitar algo em troca do respeito do agente moral. $^{11}$

Sterba ainda aponta que a igualdade entre as espécies, que possibilita que alguém prefira a si próprio ou os membros de sua espécie, pode também ser fundada na preservação. Seguindo essa fundamentação, o autor estabelece outros dois princípios para assentar o que defende por igualdade entre as espécies, os quais também se aplicam a todos os agentes capazes de entender e agir conforme eles, a saber:

O princípio de (agressão para) preservação, que permite a agressão contra as necessidades básicas de outros, quando necessária para satisfazer as próprias necessidades básicas, a menos que essas sejam proibidas.

O princípio de não-agressão, que proíbe agressão contra as necessidades básicas de outros para (1) realizar necessidades não-básicas próprias, e (2) mesmo que as realize, caso seja razoavelmente possível esperar um nível comparável de abstenção altruísta daqueles outros. ${ }^{12}$

Sterba compreende necessidades, em geral, como coisas que, se não satisfeitas, conduzem a carências ou deficiências relacionadas a vários padrões. ${ }^{13}$ Nesse sentido, os padrões humanos, de 
acordo com os quais necessidades humanas devem ser satisfeitas, estabelecem que a vida humana seja decente. E às necessidades básicas não satisfeitas de animais e plantas seguem a falta ou a deficiência relativas aos padrões de vida saudável deles.

Por outro lado, os meios necessários para satisfazer as necessidades básicas dos humanos variam de sociedade para sociedade, segundo Sterba. ${ }^{14}$ Por contraste, os meios necessários para satisfazer as necessidades básicas de espécies de plantas e animais são mais invariantes.

Para além disso, reconhece Sterba, nem toda necessidade pode ser claramente classificada como básica, ou não-básica. ${ }^{15}$ Mas, a dificuldade em se definir se uma necessidade é, ou não, básica, para se aplicar a gama de conceitos dicotômicos, tais como, moral/imoral, legal/ilegal, vivo/ não-vivo, humano/não-humano, não deve, segundo ele, nos imobilizar, especialmente nos casos nos quais se reconhece claramente o que sejam necessidades básicas e o que sejam necessidades não-básicas.

$\mathrm{Na}$ ótica de Sterba, qualquer sobrevivência requer um princípio moral de preservação que permita agressão contra as necessidades básicas de, no mínimo, algumas outras coisas vivas, a qualquer hora que for necessário para realizar os interesses básicos desse alguém ou as necessidades básicas de outro alguém que esteja sob seu cuidado. Essa satisfação ocorre de modo condizente com a moralidade presente no biocentrismo sterbiano, de acordo com uma destas duas possibilidades: ou de modo a permitir a alguém agir contra as necessidades básicas de outrem, para atender seus interesses básicos; ou de modo a alguém contrariar as necessidades básicas de outros para atender às próprias necessidades básicas, a menos que alguém possa razoavelmente esperar um nível comparável de abstenção altruísta daqueles outros.

A primeira variante do princípio de preservação, referido no parágrafo anterior, não coloca qualquer limite a quem agride a satisfação de necessidades básicas alheias. Ela permite até o canibalismo, desde que sirva para atender às necessidades básicas de quem o pratique. A segunda variante daquele princípio faz o indivíduo esperar um grau comparável de abstenção altruísta de todos que se beneficiam com a abstenção, normalmente os membros da própria espécie.

Assim, o princípio de preservação, o qual pode ser entendido como princípio de agressão para a preservação, junto com seu aliado, o princípio de não-agressão, sancionam uma certa preferência pelos membros da própria espécie do agente, na teoria sterbiana.

\section{Igualdade vs. preferência especista}

Sterba passa, então, a se interrogar se esse nível de preferência é compatível com a igualdade 
entre as espécies. Isto é, a igualdade entre as espécies, fundada sobre os dois princípios acima expostos, realmente existe? Para responder a essa interrogação, o autor passa a analisar como seria a relação entre os humanos e outras espécies de coisas vivas, caso fosse aplicada a igualdade entre as espécies, baseada naqueles dois princípios.

No caso dos humanos, adotar o primeiro princípio, o de agressão, para atender somente suas necessidades básicas, reduziria claramente o grau de predação das espécies por parte dos humanos. ${ }^{16}$ Quanto ao segundo princípio, Sterba argumenta que os pactos implícitos de não-agressão, baseados na expectativa razoável de um grau comparável de altruísmo dos sujeitos humanos, têm sido enormemente benéficos, e é provável que foram necessários para a sobrevivência da espécie humana. ${ }^{17}$

Taylor, porém, não considera que a satisfação de necessidades básicas do agente moral em detrimento da satisfação de necessidades básicas de outros seres, sejam esses da mesma espécie do agente moral, ou não, possa ser considerada legítima, se ocorrem pelo princípio de agressão ou não-agressão de Sterba. Isso porque Taylor só considera legítimo o agente moral satisfazer suas necessidades básicas em detrimento da satisfação da(s) necessidade(s) básicas(s) de um paciente moral (moral subject), quando o agente moral não possui um caminho alternativo para satisfazer essa(s) sua(s) necessidade(s). ${ }^{18}$

A possibilidade de o agente moral impossibilitar deliberadamente a satisfação de uma necessidade básica de um animal já foi aqui anteriormente explicada, quando consideramos o princípio de autodefesa de Taylor.

Porém, na visão de Sterba, requerer a igualdade entre espécies, conforme o faz Taylor, seria requerer que humanos estendessem o benefício do pacto baseado no altruísmo, ou seja, requerer que humanos fossem santos. Para Sterba, certamente, na moralidade não está em jogo a possibilidade de se requerer de alguém que seja santo. ${ }^{19}$ Assim, um maior altruísmo por parte de concepções éticas, tais quais a de Taylor, não pode ser moralmente requerido.

A visão geral da igualdade entre as espécies, de Sterba, baseia-se inicialmente em quatro princípios: dois relativos à autodefesa, justificada pela analogia que estabelece com a ética humana; e dois relativos à preservação da espécie humana. Esses princípios requerem, segundo seu autor, fundamentar a igualdade entre as espécies, a qual implica em que os interesses básicos dos membros de quaisquer espécies sejam protegidos contra ações agressivas que somente servem para realizar necessidades não-básicas dos agentes morais. ${ }^{20}$ Diante dessa implicação, Sterba estabelece, então, um quinto princípio: o da retificação. Esse implica na reparação do que foi prejudicado pela violação possibilitada pelos outros princípios, sobre o qual Sterba fundamenta a igualdade entre as espécies. Obviamente, admite, o autor, tal princípio é um tanto vago, mas para aqueles que estão dispostos a compartilhar dos outros quatro princípios, deve ser possível remediar tal vaguidade na prática. ${ }^{21}$ 


\section{Biocentrismo e harmonia natural: a crítica ao holismo de Aldo Leopold}

Após citar e justificar os cinco princípios sobre os quais funda a igualdade que defende existir numa teoria que trata todas as espécies igualmente, Sterba diz ter respondido à primeira, das três críticas que se propôs rebater em seu artigo: a de que o biocentrismo seja tendenciosamente a favor da espécie humana.

O autor passa, então, a responder à segunda crítica: a de que o biocentrismo pressupõe que haja uma harmonia na natureza, hipótese contestada por teorias ecológicas atuais. Para rebater essa crítica, Sterba precisa defender um biocentrismo que não pressuponha tal equilíbrio, ou mostrar que tais críticas estão equivocadas.

Sterba lembra aos leitores que o biocentrismo que pressupõe tal harmonia é aquele baseado na teoria holista de Aldo Leopold. Esta concepção tem a visão dos sistemas naturais como integrados, como um todo em equilíbrio e harmonia, ou movendo-se para alcançar estados de equilíbrio maduros.

Admitindo-se o biocentrismo na perspectiva de Leopold, admite-se que as prerrogativas e restrições para os agentes morais em suas relações com outras coisas vivas, isto é, o que os agentes morais estão autorizados a fazer, e o que eles não são autorizados a fazer, com respeito a outras coisas vivas, depende de se as ações são, ou não, condizentes com o equilíbrio ambiental.

Sterba, no entanto, se afasta do biocentrismo holista de Leopold. São as prerrogativas capturadas pelo princípio de defesa e pelo princípio de agressão para preservação que especificam quando os agentes morais podem justificadamente seguir seus próprios interesses e os interesses daqueles com quem eles se importam, independentemente de existir, ou não, o equilíbrio natural ${ }^{22}$. Isso, por sua vez, exclui seu biocentrismo de ser atacado por essa segunda crítica.

Taylor, por sua vez, também sustenta a concepção biocêntrica afastada da concepção ética biocêntrica de Aldo Leopold. No entanto, diferente de Sterba, fundamenta seu biocentrismo no valor inerente (inherent worth) de uma entidade viva, o qual Sterba chama de valor intrínseco. Assim, o agente moral adota a ética tayloriana quando respeita uma entidade viva, pelo fato de que ela possui tal valor. $\mathrm{O}$ agente moral tayloriano não compartilha com o agente moral de sterbiano o mesmo conjunto de prescrições morais.

Admitindo-se que não haja a pressuposta harmonia na natureza, Callicot, seguidor da teoria biocêntrica holista de Aldo Leopold, afirma Sterba, argumenta, porém, que os humanos têm responsabilidade ética, por causarem perturbações mais impactantes na natureza do que o curso natural o produz. Contra essa tese, Sterba se insurge apontando a falta de justificativa para se admitir que perturbações naturais seriam melhores que as humanas na natureza. ${ }^{23}$ 


\section{Do valor das coisas vivas e de seres vivos}

Resta ainda, a Sterba, responder à terceira das críticas ao biocentrismo a que se propõe rebater: conseguir razoavelmente distinguir a vida que os biocentristas reivindicam ter valor intrínseco, de coisas animadas e inanimadas que aqueles consideram não possuir tal valor.

Tal distinção, segundo Sterba, é de extrema relevância numa teoria biocêntrica, porque essa considera que são as coisas que possuem valor intrínseco que podem ser prejudicadas, ou beneficiadas, pelas ações humanas. ${ }^{24}$ As ações que os humanos praticam, afetando coisas que têm valor intrínseco, podem ser classificadas como éticas, ou não éticas.

Sterba começa a delimitar o conceito de valor intrínseco com a apresentação de duas visões do que seja esse valor. De acordo com a primeira delas, dizer que $\mathrm{X}$ tem valor intrínseco é dizer que $\mathrm{X}$ é reconhecido por algum agente $\mathrm{Y}$ como bom, como um fim, o oposto a dizer que $\mathrm{X}$ tem valor instrumental, que é dizer que $\mathrm{X}$ é bom como meio para algum agente. ${ }^{25} \mathrm{De}$ acordo com a primeira noção de valor intrínseco, continua Sterba, dizer que $X$ tem valor intrínseco é dizer que o bem de $\mathrm{X}$ deveria restringir o modo pelo qual outros usam $\mathrm{X}$ para realizarem seus próprios interesses. ${ }^{26}$ Então, dizer que certos seres vivos têm valor intrínseco, é dizer que o bem daquelas coisas vivas deveria constranger práticas de outros que as usam para realizar interesses próprios.

Nesse momento, Sterba recorda que as restrições reais, que operam constrangendo legitimamente caminhos de ações em que agentes morais usam coisas que possuem valor intrínseco em benefício próprio, são dadas pelos cinco princípios morais sobre os quais fundamenta e defende a igualdade entre as espécies. ${ }^{27}$

Voltando à crítica de que os biocentristas não conseguem distinguir o que possui valor intrínseco, do que não possui, Sterba aponta, que, até então, sempre houve a falta de justificativa para a não atribuição de tal valor a máquinas, rins, corações, a saber, a coisas que o biocentrismo sempre considerou destituídas de tal valor. ${ }^{28}$

Sterba passa, então, a revisar algumas definições que os biocentristas já haviam dado ao conceito de valor intrínseco, incluindo a de Taylor. Este reivindica que coisas vivas, tais quais corações e rins, não têm um bem a seu próprio modo, pois seu bem deriva de outra coisa viva que tem um bem próprio, ao qual aquelas servem. ${ }^{29}$ Algo tem valor intrínseco definido, na interpretação de Sterba $^{30}$, quando tem um bem a seu próprio modo, o que, vimos aqui anteriormente, é correto afirmar de Taylor.

Laurence Johnson, continua Sterba, responde similarmente, mas mais extensamente, reivindica que objetos ou pacientes morais (moral subjects) são sistemas vivos em um estado de entropia baixo ${ }^{31}$, sustentado por processos metabólicos de acúmulo de energia, cuja unidade orgânica 
e auto-identidade é mantida em equilíbrio pelo processo que se repete homeostaticamente. ${ }^{32}$

Entretanto, essas definições de valor intrínseco não são, na visão de Sterba, justificáveis. No seu entender, a falta de justificativa ocorre porque tais definições partem de "fatos" e não de "valores". ${ }^{33}$

Tanto Taylor quanto Johnson defendem que máquinas e coisas, corações, rins, por exemplo, não possuem valor intrínseco, porque não possuem uma configuração compatível com os fatos dos quais os autores partem para concluir que algo tem, ou não, valor intrínseco. Sterba considera que se consegue estabelecer definitivamente o que tem valor intrínseco, de modo justificado, quando esse valor deriva de valores. Esses últimos são aqueles que podem ser derivados dos cinco princípios defendidos por ele na conceituação do que seja a igualdade moral entre as espécies. Nas palavras do autor: "Particularmente é uma derivação de 'valores' de 'valores' ou de 'deveres no qual a necessidade da derivação pode ser exibida". ${ }^{34}$ Para o entendimento dessa derivação, Sterba considera necessário apresentar primeiramente um conjunto de premissas que estabelecem a abrangência da moralidade, contida naqueles cinco princípios:

(1a) Os requerimentos da moralidade não estão entre os requerimentos que seria irrazoável impor a um agente moral;

(2a) É irrazoável impor a agentes morais uma obrigação positiva para beneficiar todas as coisas capazes de serem beneficiadas e prejudicadas (tais como corações e rins, e a qualquer máquina que possua uma qualificação);

(3a) Uma obrigação positiva para beneficiar todas as coisas capazes de serem beneficiadas e prejudicadas não é um requerimento da moralidade. ${ }^{35}$

Lembrando que Sterba aponta como irrazoável algo que não pode ser exigido moralmente, de acordo com os dois primeiros princípios que oferece para fundamentar a igualdade entre as espécies, secundariamente, o autor estabelece o que, em geral, são os requerimentos da moralidade existente naqueles cinco princípios:

(1b) Moralidade impõe requerimentos razoáveis a agentes morais;

(2b) Os princípios de defesa, não-defesa, preservação, não-agressão, e retificação, diferente de outras alternativas, são razoáveis para impor deveres a todos os agentes morais;

(3b) Os princípios de defesa, não-defesa, preservação, não-agressão, e retificação, são requerimentos da moralidade. ${ }^{36}$

A partir do fato do primeiro grupo das premissas acima poder ser amplamente respeitável e moralmente justificável, e a derivação da segunda premissa ser logicamente procedente daquele 
primeiro grupo, Sterba considera ter respondido à terceira daquelas críticas. Isso porque, máquinas e coisas vivas (corações e rins), não têm valor intrínseco no biocentrismo de Sterba. De acordo com sua teoria, não é razoável impor a um agente moral o dever de respeito por uma coisa, só porque ela é viva. Além de ser viva, é necessário que os deveres provenientes do conceito de igualdade entre as espécies, de Sterba, digam que ela tem valor.

\section{Considerações finais}

Dado que o conceito de igualdade, de Sterba, se fundamenta sobre cinco princípios, e, dentre estes, há a pressuposição de necessidades básicas e não básicas, e essas necessidades são fatos, o autor estaria derivando seu conceito, de fatos, não de valores, conforme pressupõe. Logo, a crítica que faz a Taylor, de que este não justifica seu conceito de valor intrínseco, porque o deriva de fatos, o que, por sua vez, não forneceria justificativa para ser este, e não outro, fato, que dá base para tal valor, também recai sobre si próprio.

Perante a crítica de Sterba, de que a concepção tayloriana exige que o agente moral seja santo, já que Taylor exige que o agente moral estenda seu altruísmo a pacientes morais de outras espécies que não a do agente moral, e que isso é irrazoável de requerer desse agente, podemos responder com a seguinte passagem, da obra, To the Earth's Wild Living Things, de Taylor: “A significância moral que o mundo natural tem para nós depende de como olhamos para o sistema da natureza como um todo e nosso papel nele". ${ }^{37}$

Assim, segundo Taylor, o respeito pelas coisas vivas, por possuírem valor inerente, denominado por Sterba de "valor intrínseco", vai além do que o grau de altruísmo de Sterba permite, não exigindo que o agente moral seja santo, mas que as crenças de tal agente em relação à natureza sejam as que permitam conceber tal respeito moral. Essa réplica de Taylor a Sterba pode ser vista como bastante contundente, quando o primeiro observa que nossa atitude ética perante a natureza sempre depende de nossas crenças quanto ao que ela é, e quanto ao nosso papel nela. ${ }^{38}$ 


\section{Notas}

${ }^{1}$ Este artigo foi apresentado como trabalho final no Seminário de Ética Prática oferecido em 2007.2, pelo Programa de Pós-Graduação em Filosofia da UFSC, sob orientação da Dra. Sônia T. Felipe.

${ }^{2}$ STERBA, P. James. A Biocentrist Strikes Back. In: Earth Ethics: Introductory Readings on Animal Rights and Environmental Ethics. 2nd ed. Upper Saddle River, NJ: Prentice Hall, 2000.

${ }^{3}$ Idem, Ibid., p. 187-88.

${ }^{4}$ Ibid., p. 187.

5 TAYLOR, Paul. To the Earth's Living Things. Princeton: Princeton University Press, New Jersey, 1989. p. 278.

${ }^{6}$ Idem, Ibid., p. 283.

7 STERBA, P. James. Op. cit., p. 188.

${ }^{8}$ TAYLOR, Paul. To the Earth's Living Things. New Jersey: Princeton University Press, 1989. p. 265.

${ }^{9}$ Altruísmo: disposição para interessar-se pelo, ou, dedicar-se ao próximo.

${ }^{10}$ STERBA, P. James. Op. cit., p. 188-89.

${ }^{11}$ Ibid., 189.

12 TAYLOR, Paul. To the Earth's Living Thing, p. 75.

${ }^{13}$ STERBA, P. James. Op. cit., p. 189.

${ }^{14}$ Ibid.

${ }^{15}$ Ibid.

${ }^{16}$ Ibid.

${ }^{17}$ Ibid., p. 188.

${ }^{18}$ Ibid.

19 TAYLOR, Paul. To the Earth's Living Things, p. 265.

${ }^{20}$ STERBA, P. James, Op. cit., p. 190.

${ }^{21}$ Ibid., p. 189.

${ }^{22}$ Ibid., p. 191.

${ }^{23}$ Ibid., p. 192.

${ }^{24}$ Ibid.

${ }^{25}$ Ibid., p. 193.

${ }^{26}$ Ibid., p. 193.

${ }^{27}$ Ibid.

${ }^{28}$ Ibid.

${ }^{29}$ Ibid.

${ }^{30}$ Ibid.

${ }^{31}$ O que Sterba considera "valor intrínseco", Taylor denomina "valor inerente" (inherent worth).

31 Medida do nível de desordem no sistema.

${ }^{32}$ De maneira a se regular pelas leis do equilíbrio interno, que regem a composição e as reações físico-químicas inerentes ao organismo, e que, graças a mecanismos reguladores, são mais ou menos constantes.

${ }_{33}$ STERBA, P. James, Op. cit., p. 195.

${ }^{34}$ Ibid.

${ }^{35}$ Ibid.

${ }^{36}$ Ibid., p. 195-96.

37 TAYLOR, Paul. To the Earth's Living Things, p. 99.

${ }^{38}$ Ibid. 


\section{Referências bibliográficas}

STERBA, J. A Biocentrist Strikes Back. In: Earth Ethics: Introductory Readings on Animal Rights and Environmental Ethics. 2nd edition. Upper Saddle River, New Jersey: Prentice Hall, 2000.

TAYLOR, P. To the Earth's Living Things. Princeton: Princeton University Press, New Jersey, 1989. Respect for Nature: A Theory of Environmental Ethics. Princeton: Princeton University Press, 1989. 